\title{
Exploring resilience and mental health in services users and practitioners in Ireland and Canada
}

\section{Dermot Hurley \& Gloria Kirwan}

To cite this article: Dermot Hurley \& Gloria Kirwan (2018): Exploring resilience and mental health in services users and practitioners in Ireland and Canada, European Journal of Social Work, DOI: 10.1080/13691457.2018.1530644

To link to this article: https://doi.org/10.1080/13691457.2018.1530644

册 Published online: 10 Oct 2018.

Submit your article to this journal

Џll Article views: 107

View Crossmark data \lceil 


\title{
Exploring resilience and mental health in services users and practitioners in Ireland and Canada
}

\author{
Dermot Hurley and Gloria Kirwan ${ }^{\mathrm{b}}$ \\ ${ }^{a}$ King's University College - Social Work, London, Canada; ${ }^{b}$ School of Social Work \& Social Policy, Trinity College \\ Dublin, Dublin, Ireland
}

\begin{abstract}
Social work practitioners face significant challenges in their professional lives when advocating for marginalised and disadvantaged people who face deep structural inequalities, lack of resources and inaccessibility to social and health care services. Many service users are long-suffering, dispirited, and demoralised without hope for a better future. This is particularly the case in community based mental health services where social workers provide frontline counselling and advocacy to individuals with serious and persistent mental illness. Prolonged adversity takes a toll on the resilience of the service user while social work practice, aimed at counteracting such structural adversity, takes a toll on the resilience of the practitioner. Too often, community mental health agencies fail to recognise this toll and do little to support the resilience of social work practitioners. This study looks at practitioner perspectives on resilience and explores the idea of relational resilience as a buffer against burnout and compassion fatigue. The paper identifies themes from qualitative interviews with social workers on community mental health teams $(\mathrm{CMH})$ in Ireland and assertive community treatment teams (ACT) in Canada who are involved in front line mental health services. The words 'service user' and 'client' are used interchangeably to reflect common usage in the two locations.
\end{abstract}

\section{KEYWORDS}

Resilience; mental health; vicarious resilience

\section{Introduction}

Resilience can be broadly described as 'reduced vulnerability to environmental risk experiences, the overcoming of a stress or adversity, or a relatively good outcome despite risk experiences' (Rutter, 2012, p. 336). Although the promotion of resilience in mental health is a cornerstone of numerous policy documents (Mental Health Commission, 2005; Mental Health Commission of Canada, 2016) relatively little is known about the role of resilience in recovery from severe mental illness. Researchers argue that resilience is a multifaceted concept that requires an understanding of complex processes in the promotion of mental health (Davydov, Stewart, Richie, \& Chaudieu, 2010; Rutter, 2007). Multidimensional factors have been explored including neurobiological, cognitive, personality, emotional, social and spirituality (Southwick, Litz, Charney, \& Friedman, 2011). Critics argue however that a focus on personal resilience fails to account for structural factors that clearly influence mental health outcomes (Howell \& Voronka, 2012)

The resilience of both service user and practitioner is challenged in the context of community mental health work where fluctuation in resilient functioning is the norm. In this study, we define client resilience as 'the ability to utilise internal and external resources to support and maintain recovery from serious mental illness, and experience a quality of life consistent with social and cultural 
expectations' (Hurley \& O'Reilly, 2017, p. 2). CMH practitioners navigate between risk and resilience in working with clients who are living with serious and persistent mental illness (Acker, 1999; Bride \& Figley, 2007), which over time can deplete their relational capacity and their resilience. Practitioners trying to build therapeutic relationships with their clients can experience emotional exhaustion and compassion fatigue resulting in absenteeism or job change that disrupts the working therapeutic relationship (Evans et al., 2005). Here we adapt McCann et al.'s (2013) view that practitioner resilience is the ability to maintain personal and professional well-being in challenging and stressful contexts. There is some recent evidence that $\mathrm{CMH}$ teams are more vulnerable than colleagues in other mental health programmes to burnout due to job stressors such as lack of supervisory support and increased work load (O'Connor, Muller Neff, \& Pitman, 2018)

An important aspect of resilience-based work is encountering resilience in clients, which helps to sustain professional competence and commitment in the social worker (Hurley, Alvarez, \& Buckley, 2015). Positioning resilience as a relational phenomenon embedded in the collaborative therapeutic work between service user and practitioner, this paper explores the factors that promote or drain resilience of clients and practitioners in the field of mental health service delivery.

\section{Literature review}

\section{Resilience and mental health service users}

Although the field is replete with references to the importance of resilience in sustaining positive mental health, there is limited research on how to promote resilience in working with people living with serious and persistent mental illness. Promoting resilience through supportive professional relationships, self-efficacy, meaningful activities and peer support has been associated with improved recovery from mental illness (Mancini, 2007). Davydov et al. (2010) draw recommendations from the literature on how to promote resilience through anti-stress training, engaging positive emotions, exploring spirituality and exposure to manageable challenges.

Factors that have been linked to resilience in mental health recovery include individual strengths, coping skills, faith, perseverance, problem-solving, social competence, family and social supports (Meyer \& Mueser, 2011). Mental illness takes a toll on relationships due to symptoms such as apathy and a-motivation (Saunders, 2003) or to heavy sedation or medication side effects. It is also recognised that the capacity to sustain social relationships is influenced by macro factors such as social attitudes to mental illness, stigma, social exclusion and material deprivation (Barry, 2009). In addition, the reality of deinstitutionalisation has created serious barriers to mental health recovery, including poverty, homelessness, bed closures, transinstitutionalisation and burden on family members and caregivers and (Flyckt, Löthman, Jörgensen, Rylander, \& Koernig, 2013; Hudson, 2016 Isaac \& Armat, 1990; Saxena, Sharan, \& Saraceno, 2003).

A sense of personal agency can be eroded by the experience of mental illness and many service users experience exclusion from treatment decisions that impact their lives. Davies, Gray, \& Webb (2014) highlight the power imbalances that can exist between service users and service providers and they argue that tokenistic engagement with service users' views is ultimately demotivating and unhelpful in promoting personal agency. They may also experience coercion in the form of involuntary hospitalisation or other restrictive measures. McCubbin (2001) proposes a more inclusive conceptualisation of service users, which positions them as agentic individuals who can participate in decisions related to their recovery plan, a view strongly endorsed by service users in a study of participation in the Irish context (Kirwan, 2017).

\section{Resilience and mental health practitioners}

There is a growing body of research on resilience and mental health of practitioners who are engaged in psychiatric rehabilitation and trauma counselling. Much of the research focuses on secondary 
traumatic stress, compassion fatigue and burnout (Bride \& Figley, 2007). Ting, Jacobson, and Sanders (2008) found that secondary traumatic stress, negative coping and poor supervision contributed to diminish social workers' coping abilities. Huxley et al. (2005) found that organisational issues including workload pressures, staffing issues and being undervalued contributed to increased perceived stress among mental health social workers. Practitioner resilience is also linked to self-care, professional identity and values, quality supervision and positive role models (Beddoe, Davys, \& Adamson, 2011), while relationship skills, peers and supervision were also found to be protective of a worker's mental health (Adamson, Beddoe, \& Davys, 2012). Researchers have also identified positive effects of working with clients in adverse situations. Stevanovic and Rupert (2004) found that promoting growth in clients and work enjoyment were highly-rated sources of work-related satisfaction. Unexpected positive outcomes have also been identified related to the concept of vicarious resilience, human flourishing and compassion satisfaction (Alvarez \& Hurley, 2010; Hernandez, Engstrom, \& Gangsei, 2010; Radley \& Figley, 2007).

\section{The study}

The purpose of the study is to examine how social workers promote the resilience of mental health service users and also maintain their own resilience. The study also examines the concept of relational resilience that emerges in the therapeutic relationship, viewed as a dynamic process of shared success and failure, progress and setbacks, periods of crisis, stabilisation, relapse and partial recovery. To gather data for this study, a series of in-depth qualitative interviews was conducted in Ireland and Canada between 2015 and 2016 with a small sample of practising social workers on community mental health teams. In Ontario, all participants worked on assertive community treatment teams (ACT) while Irish participants were drawn mainly from CMH programmes in Dublin and Monaghan. The study examined three basic questions:

(1) What factors promote resilience in practice?

(2) What factors drain resilience in practice?

(3) How is resilience shared between service user and provider?

\section{Methodology}

The PI (DH) conducted individual interviews with Irish CMH social workers $(n=10)$ and Canadian social workers $(n=10)$ on ACT teams. The interview guide was developed from a focus group with mental health professionals. All interviews were recorded, transcribed and reviewed for narrative thematic content related to the concepts being examined. The study utilised interpretive phenomenological analysis (IPA), to explore the experiences of professionals in their work with clients. IPA was chosen in order to gain insight into how practitioners in a particular context of practice make sense of their work experience. The study followed an inductive, iterative approach based on contextualised and detailed accounts of social work experience. Analysis and interpretation involved a process of coding, organising, integrating and interpreting data as well as independent audit of the analysis as an acceptable form of cross-validation. The analysis identified what was distinct and what was common among the participants. Triangulation was achieved by listening to audiotapes of the interviews, reviewing field notes and a brief questionnaire. Thematic analysis for each cohort was conducted separately, followed by the development of a master theme list that included findings from both sets of interviews. Respondent validation in Canada took the form of an interactive presentation with selective participants who offered feedback on the themes that were identified. Respondent validation in Ireland was achieved by having participants review narrative data and emergent themes (by email) based on their recorded interview. There was also rigorous crossvalidation by the co-investigators who reviewed the material separately and linked themes to 
transcripts that were provided. Ethical approval was granted by King's University College at Western, Ontario and Trinity College, Dublin.

\section{Results}

\section{Note: (I) Irish social workers; (C) for Canadian social workers}

Both groups of social workers deal with clients who experience serious and persistent mental illness including a number of homeless service users. The analysis revealed points of convergence and divergence across both groups reflecting local conditions in both countries. Practitioners reported a number of stressors in accessing services for clients with very complex needs. A primary concern in both jurisdictions is the provision of supportive housing, particularly in Dublin, which is experiencing a homelessness crisis. Practitioners are also experiencing patient overload because of staff shortages and funding deficits that directly impact the resources available in the community. As one Irish social worker put it:

There is a severe housing crisis in Dublin with hundreds of people homeless with no safe place to call home, telling people that you have nowhere to house them is particularly hard! how are you ever going to begin their recovery or address some of their trauma if they don't have a safe place to call home or somewhere they feel secure?

In Ireland, despite ambitious policy targets (DECLG, 2013) the availability of resources to those most in need across society remains constrained in the aftermath of the Celtic crash. For example, the availability of accommodation in hostels and shelters is at a critical level (Prinsloo, Parr, \& Fenton, 2012). In the context of a general housing crisis in Ireland, which has elevated the demand for housing and forced many newcomers into homelessness, meeting the needs of those with mental illness who also lack accommodation continues to prove highly problematic (Ceannt, Macdonald, Fenton, \& Larkan, 2016). Structural issues, including social inequities, stigma, discrimination, poverty and homelessness, have been identified repeatedly as contributing to serious mental health problems in Canada particularly among aboriginal communities. However serious regional and geographic disparities continue to exist despite a commitment to develop a social justice framework for mental health recovery (Mental Health Commission of Canada, 2016).

\section{Factors that promote service user resilience}

Resilience is dependent on the availability of factors that include a range of relationship-based, therapeutic, practical supports and services such as a multidisciplinary team, community and carer supports. Relationship-building was noted by participants to be the cornerstone of social work practice: 'Keep empathy at the core of what you do, you need to care more not less!' (I).

However, it is under stress: 'If anything, it's become harder! I see in the field of mental health a move away from that connection with people' (I).

For the participants, promoting the resilience of service users was viewed as important and they emphasised the strong connection between resilience and recovery:

The level of resilience that somebody has is going to determine ... to a degree, the level of the outcome, because I think for a lot of people if they aren't preconditioned with resilience it's difficult for them to recover I think it's one of the pillars of recovery. (I)

Identifying resilience by inviting service users to talk about what they have been through in life is another way to promote resilience:

I think it's the people who have come through hardships, the people that have built up resilience are the people who live to tell you about it, and I think if we listen to them, even being able to tell their story gives them-empowers them to reengage with that as well. (I)

The same social worker went on to say that: 
I think it's when we can pinpoint that there have been issues in the past that they have come through, without dredging up bad memories, which is kind of what you try to avoid with that situation. It's about looking at ... what strengths ... they called upon to ... get through those situations. (I)

All participants acknowledged the importance of a strengths-based perspective in their work:

I suppose it's coming a little bit from a strengths perspective point of view, allowing them ... to re-engage with that strength, I think minimizing the social work role and making it all about them, I suppose I'm the cab but they're the driver. (I)

From the Canadian social work perspective the distinction between 'recovering from mental illness' and 'recovering in mental illness' (Davidson \& Roe, 2007) is central to how many ACT clinicians view recovery, with the emphasis on the latter while acknowledging the challenges of long-term illness. Social workers place a strong emphasis on preventing relapse by engaging clients soon after discharge from hospital: 'resilience is leaving hospital and making it in the real world, that's where we need to be!' (C).

The availability of ACT teams is considered essential to the preservation and promotion of resilient mental health functioning: 'Being hospitalized really drains resilience, if we didn't have 24/7 availability like we have they would be in and out of hospital all the time and would not be able to function in the community'(C). Activities most frequently associated with promoting resilience in ACT clients are focusing on client strengths, staying on medication, engaging in social and recreational activities, a strong focus on psycho-social rehabilitation and recovery planning. Participants spoke about the importance of supporting clients through relapse and recovery:

So what! Maybe it didn't work out one time and you ended up back in hospital, we're going to keep trying and that doesn't mean that for life you're going to be observed on medications. (C)

Social workers strongly endorsed an approach that encourages more service user participation and self-management :

We're a rehab focused team, we're not here to forever take you to doctors' appointments or forever take you to grocery shopping and doing these things, we're here to build your skills so you can do this on your own and you are capable, so whenever we see capabilities we build on that. (C)

This is consistent with the contention that resilience results from facing adversity rather than avoiding it (Rutter, 2007). ACT clinicians also spoke about the importance of conveying a sense of hope for the future:

I think we always have to have faith that people have resilience and that people are capable of moving forward from whatever illness they're dealing with. If you don't have hope that people are going to recover then where do you go from there? (C)

\section{Factors that promote practitioner resilience}

\section{Individual factors}

Most participants reported developing resilience by managing their work effectively and through self-care activities. Planned breaks from work and stress containment are seen as helpful in maintaining resilience: 'I have two young children and a very busy family life at home and that actually has improved my stress levels, amazingly because I get better at work and I can't afford to be bringing that stress home' (I). Self-advocacy is also critical to remaining resilient: 'Over the last 10 years I have learned to be resilient through very stressful times, I got better at saying no!' (I). As one Canadian participant said 'When I get home in the evening the first thing I do is change my clothes, it's sort of a boundary l've created between work and home' (C).

\section{Mindset}

Participants in both groups made quite similar observations on the importance of a resilient mindset. This includes being positive, realistic, flexible in engaging clients, focusing on recovery, encouraging 
efficacy and problem-solving and knowing the limits of what social work can achieve. 'I always remind myself that my life is not my work, the client's problem is not mine!'(I)

Working in this area I had to scale back my expectations, which is something that I had to work on, so that if someone turned up to an appointment that's an achievement, which is resilience in itself! (I)

Managing expectations of what one can do is essential to a resilient mindset:

Letting things go is very important ... you're not in control, they're in control of their lives ... you can only do what you can do and you just try and put your best foot forward and you know that sometimes you can't change certain things, you can just change how you chose to react. (C)

There is a continuous adjustment of expectations and a need to reframe success in therapeutic work: 'you need to change your mindset of what success is, success could be that they got out of bed or they took out their own garbage, that's a huge success, be happy and grateful and celebrate that'(C).

Practitioners spoke of the importance of modelling a different affective tone to counteract client self-defeating statements and expressing encouragement in various aspects of the client's life:

you need a mindset that is eternally optimistic, sort of never losing hope for what our clients are capable of, someone who finds the people they work with interesting or wonderful because, yes they have an illness but isn't it amazing that they are so interested in art or music or whatever. (C)

\section{Team as buffer}

'You learn resilience by watching colleagues' (I) Participants strongly affirmed the importance of teamwork in community mental health: 'My resilience is reflecting on my own practice with my team' (C). They also reported enjoying a degree of professional autonomy and respect. Generally, they feel valued on multidisciplinary teams where their opinions are respected. For the most part, the team is viewed as a source of inspiration and support, providing a much-needed forum for discussion of their work: 'Sharing the responsibility is the key thing for me, I'm not alone in working with this person. The decisions made are not mine alone!' (C). Team meetings (more frequent on ACT teams than $\mathrm{CMH}$ teams) and the availability of personal supervision are viewed as sustaining resilience: 'Supervision is good for resilience, I need to check in, am I doing the right thing?' (I). Peer support was endorsed in both groups: 'Having a strong working relationship with colleagues allows ... you to feed off their resilience, ... from a professional stand point ... . kind of collective resilience' (I). Another participant spoke of the benefits of a positive team culture where support is freely available:

So I have my days when my resilience is tested because I don't have that sense of accomplishment, because I can't see the progress in my work, or it's not happening as fast as I want it to, but that's where it's good to have other team members who can say, But look! She's taking the bus now and she never did that before!. (C)

Inter-professional collaboration on ACT teams includes daily briefings, shared caseloads, client reviews and a pooling of resources all of which contribute to a sense of increased support and collegiality among team members. One participant spoke of their relationship with the team in the following manner: 'Even though we sometimes cause each other distress, our team is resilient because we have each other, we're not alone, ever!'(C). Practitioners spoke of the 'wear and tear' of dealing with severe and persistent mental illness and the 'roller coaster' ups and downs related to client improvement and set-backs. The role of the team in buffering stress is strongly valued among Canadian social workers and is reflected in the following comment: 'There's a direct link between a team that supports the resilience of the worker and the clinician's role in supporting the resilience of the client' (C). Social Workers on ACT teams are aware of the importance of parallel process in supervision, where what happens in the relationship between the supervisor and clinician is mirrored in the relationship between the clinician and the client. One clinician observed that: 
We sometimes forget how important it is that people have a positive self-concept that gets reflected in the messages that we send, and for me a lot of that comes from having a coordinator who is very supportive and encouraging of my development as a professional. (C)

Effective supervision that respects clinician resilience contributes to promoting a positive team culture and is reflected in a parallel positive process between clinician and client. On the other hand, poor supervision or the lack of it results in negative outcomes: 'how can you support the resilience of the client if your supervisor is not supporting the resilience of the worker?'(C).

\section{Factors that deplete service user resilience}

Social work practitioners were forthright in expressing their exasperation with aspects of the mental health system, which depletes resilience. The Irish participants spoke at length about barriers and systemic problems in the organisation of mental health care: ' $90 \%$ of what we do drains service user resilience, the system is designed to de-skill, demoralize and create dependency' (I). For Irish social workers, some systemic issues are particularly difficult to navigate, such as change of care team when a patient is hospitalised, gaps in continuity of care, ineffective discharge-planning policies, the revolving door syndrome, and paternalistic approaches to patient care described as 'we know better attitude' (I). The following statements capture the sentiments expressed by $\mathrm{CMH}$ social workers in the study:

Involuntary admissions are very disempowering! Patients lose a right to confidentiality, its much looser speaking to their family without consent. (I)

Even when the client is resilient, it's the services that are putting people under pressure. (I)

In adult mental health services I had a fairly sharp awareness of how stigmatizing, and difficult it is for people to lead typical lives when they have chronic mental health problems. (I)

We need to support very stressed out, burnt out carers and parents, I try to make sure that the best support package is around them and they know who to go to when they need that support. (I)

Similarly, Canadian social workers identified factors that drained service user resilience, which include living with serious and persistent mental illness, medication side-effects particularly over-sedation, lack of client insight into the nature of their illness and stressors that trigger relapse including living conditions, poverty and social environments. They also voiced opinions about the inadequacy of the mental health system including ACT teams that lack flexibility and innovation: 'We have an incredible pool of talent on our team, there is so much more we could do, we need to change this model drastically' (C). Other issues identified by both groups include the lack of home-based treatment, and the growing culture of managerialism: 'Too often we just copy the UK focus on following procedures and protocols' (I).

\section{The role of medication}

There was ambivalence about the role of medication in facilitating recovery, which one participant described as:

disabling client resilience because it gives people an external ... temporary plaster, band aid, to put over the problem, because when they stop taking the medication they relapse. And I know that there are certain conditions that require medication, but it definitely... lowers the levels of resilience that people can build up because ... it doesn't ... oblige them to engage with themselves as the main source of their own recovery. (I)

Echoing Moncrieff (2011), there was a sense that 'medicating life's difficulties' is too narrow a view to take in community mental health work. Others spoke of the consequences of coming off medication:

there are a good few of our clients that would like to come off their meds and we have a very frank conversation with them ... some say they don't need it but have to take it or else they'll be sectioned! (I) 
Social workers on ACT teams were uncomfortable with their role in supervising medication compliance: 'I just hate having to stand there and watch them take their meds, it's not what I trained as a social worker to do' (C). Other participants avoid losing client trust through inappropriate, coercive or untimely intervention: 'They may not trust the medication or that they need to take it, but they trust us! They give that faith to us, that we have their better interest at heart, so I think that's a form of resilience' (C).

\title{
Factors that deplete practitioner resilience
}

Social workers are not immune to compassion fatigue and burnout and their resilience is influenced by how they perceive the effects of the psychiatric system on their clients' lives. Chief among their frustrations are the following:

There's a refusal to look at how the system is contributing to burn out by focusing on individual factors, we don't look at the consequences of stress on staff and even if we did we don't have the resources to address it. (C)

Some of these are endemic to how mental health services are organised: 'From the perspective of the organization, supporting resilience in the social worker is by default, more by accident than design!' (I). Participants spoke of the need for managers to be attuned to their level of stress: 'You need people at pivotal points within an organization who have the perspective around social worker welfare and self -care. If it's not coming from the management side it's not going to come; (C). Main stressors for community mental health services in Ireland are lack of therapeutic resources and lack of communitybased services: 'There are some really good services but there's just not enough of them' (I). 'regimented referral and acceptance drains people when they are crying out for help! they have accepted that they have a mental illness and it's taken them that long to get there and then it's 'sorry you don't fit our criteria' (I).

It appears that many of the barriers that drain service user resilience have a similar effect on practitioners:

\footnotetext{
I feel that we're not helping everyone we can or providing the services for everyone we can and that's draining! I suppose people who get into this area of work have that empathy and sometimes I'm worried that I've become desensitized to what people are going through, it's the barriers I find really tough. (I)
}

\begin{abstract}
Sometimes our team is not very healthy and the dynamics spill over on to the clients, there are people who don't understand the recovery model and adopt a very paternalistic attitude with clients and we all see it but we don't say anything about it. (C)

working within the medical model can condition social work practitioners to buy into the medical model as the source of recovery, not a helping factor but the actual source of the recovery and it not only deconditions the resilience of the service user but definitely deconditions the resilience of the practitioner. (I)
\end{abstract}

The importance of building resilience through on-going education and skill development is common to both groups: 'I find that the better you get at your job, the more resilient you become' (C) Social work is now a regulated profession in both countries, which contributes to a sense of professional identity and esteem: 'My professional identity is very important to me, we've been regulated now by the College for many years and I think we're the better for it' (C). Similar sentiments were expressed in Ireland: 'Social workers only recently have become a registered profession so now we have a responsibility for continued professional development' (I).

\section{Shared resilience}

There is much satisfaction in seeing clients doing well. The participants endorsed the idea of resilience as a shared relational phenomenon: 'I love to see people starting to live their life again and knowing that my support has helped' (I). Participation in therapeutic work with service users is highly valued: 
At the end of a good session with a service user I feel a joy, a lightness, a feeling of 'they've got through it', it puts things into perspective, it reinforces competence when someone says 'since I've seen you I've been doing all the things I want!'. (I)

The following statements capture a range of responses that underscore resilience as a shared process and the satisfaction of participating in positive outcomes:

if that person can get through that, that people bounce back from diversity or hardships you know, then what's to say I can't get through something that I'm going through? I think it definitely has that knock-on effect. (I)

These clients are still moving forward despite everything and it really humbles me! Feeding off resiliency gives me the energy to continue to do my work and also provides opportunities to reflect on what is and what is not important in life! (C)

I just love watching people make that recovery, achieving a level of self-awareness feeling 'I can cope with this' it's a lovely feeling to see this, the fact that I've been able to do my job with a level of wellness that impacts on them, even on the bad days I couldn't imagine myself doing anything else. (I)

I've definitely been astounded by a lot of clients I've worked with and I've learned a lot! I think the day you stop learning is the day you pack it in. (I)

Every day I learn from my clients, not only about my own mental health but how to stay resilient myself by helping them become more resilient. (C)

Understanding what shared resilience actually means and how it is maintained is an important area of inquiry for this study. It confirms the observation that doing meaningful work in an ethically responsible way provides benefits for the practitioner as well as the service user. It is an area that is often overlooked in therapeutic work as practitioners may not recognise the impact on their own resilience through engaging with resilient clients. The following quotes indicate a growing awareness of this phenomenon and illustrate the nature of shared or vicarious resilience:

What promotes my resilience is working with my clients on a regular basis, seeing them achieve their goals, whether they're big or small, their successes can be big or small also. (C)

So it's sort of like for me my resilience is my relationship with these people, and the enjoyment that I get from the time that I get to spend with them and that they're all unique. (C)

Every day I learn something new about life from working with my clients, I feel I have a much deeper understanding of my own mental health which makes me more resilient. (C)

You do the job because that's what you want to do in life, it's very satisfying to play a part in the client's success. (I)

In contrast to some of the negative outcomes reported by practitioners who are exposed to client trauma and adversity (Bride \& Figley, 2007), these comments reflect positive outcomes and work satisfaction related to human flourishing. The participant statements provide support for the notion of resilience as a shared, mutually beneficial, dynamic phenomenon that can develop between service user and practitioner. However, clinicians also express caution about taking credit for positive outcomes that clients have achieved:

I try not to be over invested, I don't want the client's success to by my success, but I'm proud and so happy and yes, I'm joyful when things go good for my clients in the direction that they want them to go. (C)

On the other hand, practitioners are aware of lapses in their own resilience: 'Do I get something back? Not as much as I used to! sometimes I don't feel as resilient as my clients, many times I feel I'm letting them down, I need proper supervision and support' (I).

The study found that practitioners, even when experiencing emotional exhaustion and compassion fatigue, can be strengthened in their work by vicariously experiencing service users progress and resilience, which in turn helps sustain professional competence and commitment. The research points to a bi-directional sharing of resilience in which both the practitioner and the service user are impacted by the resilience of each other. The research suggests that resilience can be fostered by 
witnessing or participating in another person's resilience. One participant offered an analogy of how resilience operates in people's lives:

It's kinda like you know your body building up resistance to antibiotics or whatever it might be? I think that people that are constantly exposed to hardship will build up resilience to combat that or to lessen the impact it has on them. (I)

Practitioners suggest resilience strengthens the therapeutic relationship, making it easier to work with service users:

I think when you meet somebody that has resilience it's so much ... easier to work effectively with this person, because they're motivated. They have that innate ability to overcome obstacles, to overcome crises, and so on. And I think when you can ... acknowledge or when you become aware of that in a client, I think you feed off that positivity. (I)

\section{Discussion}

\section{Similarities and differences between groups}

Both participant groups deal with people living with serious and persistent mental illness who are experiencing the continuing legacy of de-institutionalisation and underfunding of communitybased mental health services. Though drawn from different cultural locations, both groups share similarities as well as differences related to policies and practices. Similarities include: team support in sustaining practitioner resilience; the significance of the therapeutic relationship in promoting service user resilience; structural and systemic barriers that drain resilience and shared resilience as a dynamic process between client and practitioner. Differences were notable in how social workers talked about these issues depending on the location of the study.

Practitioners spoke of the factors that drain service user resilience, including medication use and strong sedation. In Ireland, social workers tended to question the role of medication whereas Canadian social workers saw it as a key component of the recovery process. ACT team social workers were generally less concerned than their Irish counterparts about the availability and role of psychiatrists. This is perhaps related to the evolving pattern of non-hierarchal team structure and shared leadership between disciplines on ACT teams in Ontario. A study by Maddock (2015) revealed the underlying tensions that can exist in mental health services in Ireland, a factor he linked with challenges to the dominant medical perspective in the Irish mental health service system. Availability of psychiatrists would seem to be somewhat better in Canada, where the role of consultant on ACT teams is more integrated than $\mathrm{CMH}$ teams in Ireland and includes in most cases continuing hospital care by ACT psychiatrists. The different mental health policies in Ireland and Canada affect front-line social work practice. For example, prescribed social work roles on ACT teams contrast sharply with less structured social work roles on $\mathrm{CMH}$ teams. Also, supervision tends to be readily available and more structured on ACT teams in contrast to $\mathrm{CMH}$ teams. Irish participants in the study displayed greater appreciation of the importance of the client's social ecology (Ungar, 2011) in promoting resilience through caregiver support, a concern for social justice, advocacy for service users and facilitating community resources.

In summary, we found that Irish social workers tended to be more system or macro-focused while Canadian social workers tended to be more client- or micro-focused. Participants in both groups spoke about barriers to services and its effect on their clients and themselves.

\section{Value of service}

Both Canadian and Irish social workers value their contribution to better client functioning and lower rates of re-admission to hospital. Practitioners stressed the significance of the service user-practitioner relationship in the recovery process and the importance of social work availability in responding to their clients. 
The participants regarded the team as an important buffer against burnout and compassion fatigue. Irish social workers tended to place emphasis on personal responsibility for maintaining one's own resilience whereas Canadian social workers tended to look to the mental health agency as an expected source of support and renewal. In both groups, there is a sense that professional identity and belonging to a professional body is protective of resilience. The availability of $\mathrm{ACT} / \mathrm{CMH}$ teams is considered essential to the preservation and promotion of resilience and mental health functioning including the availability and support of the supervisor/manager. This is consistent with a study on protecting practitioner resilience by McCann et al. (2013) which reinforced the benefit of resilience-promoting environments within professions. Participants in this study also acknowledge the benefits gained from working with resilient clients.

\section{Summary}

This research identified themes that are important in promoting resilience, including a focus on the ecology of people's lives, client strengths and therapeutic collaboration. Participants stressed the importance of reciprocity in maintaining resilience for both service users and practitioners through establishing and preserving strong service user-practitioner relationships. Shared resilience is a similar concept to 'vicarious resilience' (Hernandez et al., 2010), which is a unique relational phenomenon in therapeutic work. Practitioners who have an emotional investment in their client's recovery are impacted by small improvements in their clients' lives and participate vicariously in their resilience. Shared resilience is also recognised as a key component among team members who play an important role in supporting the resilience of peers. However, supportive relationships can only go so far in sustaining resilience and it is important to acknowledge how negative systemic and structural factors can drain service user and practitioner resilience.

\section{Conclusions and limitations}

This study sought to elicit the views of community mental health social workers in Canada and Ireland who offered a range of views on their work in community mental health. Practitioners noted the importance of relationship-based practice because of its positive contribution to both service user and worker resilience. The study thus identified shared resilience as a relational dynamic between service user and practitioner and a key ingredient of well-functioning teams. They linked improved mental health functioning in service users to resilience-promoting activities in recovery-based work. Resilience-informed supervision could help supervisors and social work practitioners reflect on and maintain a focus on the importance of shared resilience in promoting mental health.

One implication of the study findings is that promoting resilience should be a part of education and training for mental health practitioners (McAllister \& McKinnon, 2009). However, one needs to be careful about focusing exclusively on promoting resilience without examining how resilience relates to improved quality of life for people living with serious mental Illness (Corring et al., 2010). Lastly, the ubiquity of the term 'resilience' in mental health discourses has been criticised for implying that individuals can recover from exposure to adversity regardless of the structural barriers they have to deal with in life (Howell \& Voronka, 2012). Individualising resilience obscures the structural causes of mental health issues and minimises the experiences of inequality and social justice (Harper \& Speed, 2012). In this regard, we agree with the position of Drake \& Whitley that recovery from serious mental health problems is impeded by multiple adversities including the mental health system (Drake and Whitley (2014).

Although the number of participants in this study was relatively small $(n=20)$, saturation was reached in both locations and the interviews yielded useful qualitative data, though we recognise that participant views cannot be taken to be representative of social workers in either jurisdiction. The research is best understood as a snapshot or preliminary investigation that indicates some trends and processes that can inform resilience-based practice. A significant limitation of the study 
is the absence of the voice of the consumer of mental health services. Incorporating the lived experience of service users in the co-production of knowledge is essential for good social work research. Input from service users and carers would deepen our understanding of the concept of shared resilience and provide a more informed view on how relationships help sustain resilience in social work practice. Despite these limitations, the study has illuminated the concept of resilience as a core component of effective mental health practice.

\section{Disclosure statement}

No potential conflict of interest was reported by the authors.

\section{Notes on contributors}

Dermot Hurley is an Associate Professor of Social Work at King's University College, London, Ontario, Canada and is also a registered social work practitioner in child \& family therapy. His main area of research is promoting resilience in social work practice and he has completed studies with colleagues in Argentina, Canada and Ireland in child protection and mental health. He has published articles in the Journal of Social Work and Mental Health, the Journal of Systemic Therapy and the Canadian Social Work Review.

Gloria Kirwan is Assistant Professor of Social Work at Trinity College Dublin, Ireland. She is also a registered social worker and has a special interest in mental health social work both as a practitioner and a researcher.

\section{References}

Acker, G. M. (1999). The impact of clients' mental illness on social workers' job satisfaction and burnout. Health \& Social Work, 24(2), 112-119.

Adamson, C., Beddoe, L., \& Davys, A. (2012). Building resilient practitioners: Definition and practitioners understandings. British Journal of Social Work, 32(1), 100-117.

Alvarez, L., \& Hurley, D. (2010). Desde La zona de riesgo a la zona de resiliencia [From the zone of risk to the zone of resilience]. Revista Cientifica de UCES, 14(2), 13-36.

Barry, M. M. (2009). Addressing the determinants of positive mental health: Concepts, evidence and practice. International Journal of Mental Health Promotion, 11(3), 4-17.

Beddoe, L., Davys, A., \& Adamson, C. (2011). Educating resilient practitioners. Social Work Education, 1, 1-18.

Bride, B. E., \& Figley, C. R. (2007). The fatigue of compassionate social workers: An introduction to the special issue on compassion fatigue. Clinical Social Work Journal, 35(3), 151-153.

Ceannt, R., Macdonald, S. H.-F., Fenton, J., \& Larkan, F. (2016). Circles within circles: Dublin's frontline homeless sector workers discuss the intersectional issues of homelessness, mental illness and addiction. European Journal of Homelessness, 10(2), 61-86.

Corring, D. J., Anders, K., Bateman, L., Harshaw, S., Shlomovitz, E., Diaz, K., \& Peer, I. (2010). Perspectives on their quality of life provided by persons with serious mental illness who are on a community treatment order: A naturalistic enquiry involving 'critical case sampling'. Research Insights; Regional Mental Health Care London and St. Thomas, 7(2), 1-9.

Davies, K., Gray, M., \& Webb, S. A. (2014). Putting the parity into service-user participation: An integrated model of social justice. International Journal of Social Welfare, 23, 119-127.

Davidson, L., \& Roe, D. (2007). Recovery from versus recovery in serious mental illness: One strategy for lessening confusion plaguing recovery. Journal of Mental Health, 16(4), 459-470.

Davydov, D., Stewart, R., Richie, K., \& Chaudieu, I. (2010). Resilience and mental health. Clinical Psychology Review, 30(5), $479-495$.

DECLG (Department of the Environment, Community and Local Government). (2013). Homelessness policy statement. Dublin: Author.

Drake, R. E., \& Whitley, R. (2014). Recovery and severe mental illness: Description and analysis. Canadian Journal of Psychiatry. Revue Canadienne de Psychiatrie, 59(5), 236-242.

Evans, S., Huxley, P., Gately, C., Webber, M., Mears, A., Pajak, S., ... Katona, C. (2005). Mental health, burnout and job satisfaction among mental health social workers in England and Wales. The British Journal of Psychiatry, 188(1), 75-80.

Flyckt, L., Löthman, A., Jörgensen, L., Rylander, A., \& Koernig, T. (2013). Burden of informal care giving to patients with psychoses: A descriptive and methodological study. The International Journal of Social Psychiatry, 59(2), $137-146$. doi:10.1177/0020764011427239

Harper, D., \& Speed, E. (2012). Uncovering recovery: The resistible rise of recovery and resilience. Studies in Social Justice, 6 (1), 9-25. 
Hernandez, P., Engstrom, D., \& Gangsei, D. (2010). Exploring the impact of trauma on therapists: Vicarious resilience and related concepts in training. Journal of Systemic Therapies, 29(1), 67-83.

Howell, A., \& Voronka, J. (2012). Introduction: The politics of resilience and recovery in mental health care. Studies in Social Justice, 6(1), 1-7.

Hudson, C. (2016). A model of deinstitutionalization of psychiatric care across 161 nations: 2001-2014. International Journal of Mental Health, 45(2), 135-153.

Hurley, D., \& O'Reilly, R. (2017). Resilience, mental health and assertive community treatment. Social Work in Mental Health. doi:10.1080/15332985.2017.1302038

Hurley, D., Alvarez, L., \& Buckley, H. (2015). From the zone of risk to the zone of resilience: Protecting the resilience of children and practitioners in Argentina, Canada and Ireland. International Journal of Child, Youth and Family Studies, 6(1), 17-51.

Huxley, P., Evans, S., Gately, C., Webber, M., Mears, A., Pajak, S., ... Katona, C. (2005). Stress and pressures in mental health social work: The worker speaks. British Journal of Social Work, 35, 1063-1079.

Isaac, R. J., \& Armat, V. C. (1990). Madness in the streets: How psychiatry and the law abandoned the mentally ill. New York, NY: Free Press.

Kirwan, G. (2017). Mental health service users' narratives of participation: Consensus, dissensus and paradox (Unpublished thesis). Trinity College Dublin.

Maddock, A. (2015). Consensus or contention: An exploration of multidisciplinary team functioning in an Irish mental health context. European Journal of Social Work, 18(2), 246-261.

Mancini, M. (2007). The role of self-efficacy in recovery from serious psychiatric disabilities: A qualitative study with fifteen psychiatric survivors. Qualitative Social Work, 6(1), 49-74.

McAllister, M., \& McKinnon, J. (2009). The importance of teaching and learning resilience in the health disciplines: A critical review of the literature. Nurse Educ Today, 29(4), 371-379.

McCann, C. M., Beddoe, E., McCormick, K., Huggard, P., Kedge, S., Adamson, C., \& Huggard, J. (2013). Resilience in the health profession: A review of recent literature. International Journal of Well-Being, 3(1), 60-81.

McCubbin, M. (2001). Pathways to health, illness and well-being: From the perspective of power and control. Journal of Community \& Applied Social Psychology, 11(2), 75-81.

Mental Health Commission. (2005). A vision for a recovery model in Irish Mental Health Services. Discussion Paper by MHC, Ireland.

Mental Health Commission of Canada. (2016). Mental Health Commission of Canada strategic plan: $2017-2022$.

Meyer, P. S., \& Mueser, K. T. (2011). Resiliency in individuals with serious mental illness. In S. M. Southwick, B. T. Litz, D. Charney, \& M. J. Friedman (Eds.), Resilience and mental health: Challenges across the lifespan (pp. 276-289). Cambridge: Cambridge University Press.

Moncrieff, J. (2011). The myth of the antidepressant: An historical analysis. In M. Rapley, J. Moncrieff, \& J. Dillon (Eds.), DeMedicalizing misery: Psychiatry, psychology and the human condition (pp. 174-189). Basingstoke: Palgrave Macmillan.

O'Connor, K., Muller Neff, N., \& Pitman, S. (2018). Burnout in mental health professionals: A systematic review and metaanalysis of prevalence and determinants. European Psychiatry, 53, 74-99. doi:10.1016/j.eurpsy.2018.06.003

Prinsloo, B., Parr, C., \& Fenton, J. (2012). Mental illness among the homeless: Prevalence study in a Dublin homeless hostel. Irish Journal of Psychological Medicine, 29(1), 22-26.

Radley, M., \& Figley, C. (2007). The social psychology of compassion. Clinical Social Work Journal, 35, $207-214$.

Rutter, M. (2007). Resilience, competence, and coping. Child Abuse \& Neglect, 31, 205-209.

Rutter, M. (2012). Resilience as a dynamic concept. Development \& Psychopathology, 24, 335-344.

Saunders, J,C. (2003). Families living with severe mental illness: A literature review. Issues in Mental Health Nursing, 24(2), $175-198$

Saxena, S., Sharan, P., \& Saraceno, B. (2003). Budget and financing of mental health services: Baseline information on 89 countries from WHO's project atlas. Journal of Mental Health Policy and Economics, 6(3), 135-143.

Southwick, S., Litz, B., Charney, D., \& Friedman, M. (2011). Resilience and mental health: Challenges across the lifespan. Cambridge: Cambridge University Press.

Stevanovic, P., \& Rupert, P. A. (2004). Career-sustaining behaviors, satisfactions, and stresses of professional psychologists. Psychotherapy: Theory, Research, Practice, Training, 41(3), 301-309.

Ting, L., Jacobson, J. M., \& Sanders, S. (2008). Available supports and coping behaviors of mental health social workers following fatal and nonfatal client suicidal behavior. Social Work, 53(3), 211-221.

Ungar, M. (2011). The social ecology of resilience. Addressing contextual and cultural ambiguity of a nascent construct. American Journal of Orthopsychiatry, 81, 1-17. 